\title{
Coastal Reclamation Impacts to the Quality of Life: Tanjung Tokong, Penang
}

\author{
Nadzhirah Mohd Nadzir¹, Mansor Ibrahim¹, Mazlina Mansor² \\ ${ }^{1}$ Department of Urban and Regional Planning, Kulliyah of Architecture and Environmental Design, \\ 2 Department of Landscape Architecture, Kulliyah of Architecture and Environmental Design, \\ International Islamic University Malaysia, Malaysia \\ nadzhirahnadzir@gmail.com, profmansor@iium.edu.my, mazlina.mansor@gmail.com
}

\begin{abstract}
The impacts of coastal reclamation to the coastal community have usually been overlooked. This paper presents the impacts of coastal reclamation to the quality of life of Tanjung Tokong's community. The questionnaire survey data was analyzed using Statistical Package for Social Science (SPSS), and the interview was content analyzed. The results show only three variable, influenced quality of life the most. Flash flood and traffic congestion negatively correlated with quality of life while health positively correlated with quality of life. It recommended that the coastal reclamation process should consider any temporary and permanent negative impact to the community.

Keywords: Coastal Areas; Coastal reclamation;Quality of life;Social Impacts.

eISSN 2398-4279 @ 2018. The Authors. Published for AMER ABRA cE-Bs by e-International Publishing House, Ltd., UK. This is an open access article under the CC BY-NC-ND license (http://creativecommons.org/licenses/bync-nd/4.0/). Peer-review under responsibility of AMER (Association of Malaysian Environment-Behaviour Researchers), ABRA (Association of Behavioural Researchers on Asians) and cE-Bs (Centre for EnvironmentBehaviour Studies), Faculty of Architecture, Planning \& Surveying, Universiti Teknologi MARA, Malaysia.

DOI: https://doi.org/10.21834/ajqol.v3i9.77
\end{abstract}




\subsection{Introduction}

Knowingly, most of the population can be found living close to the coastal area as compared to other area (Majid, 1985). It supported by UNEP RRCAP (2004) who stated rapid economic and industrial growth have attracted an increasing percentage of the population to live in a coastal area. Because of that, in Southeast Asian, coastal zones utilized for a variety of purposes such as tourism, fisheries, transportation, mining and communication (as cited in Swaminathan, 2008). Pomeroy (1994); Dutton \& Hotta, (1995); Pomeroy, (1995); UNEP, (2001), supported by mentioning estuaries provide a variety of economic functions including supporting aquaculture activities and facilitating navigation.

Still, evident had shown that human faces shortage of land resources. For example, Xu \& Wang (2003) stressed out in the 21th century it estimated that the population of China will increase from 200 million to 300 million. However, the total farmland will reduce to $1,800 \mathrm{~km}^{2}$. By that time, China will need 400 million to 500 million population's existing spaces. Therefore, coastal reclamation is one of the solutions to increase the resources of shoreline and harbor tract. Not only China but Singapore, Hong Kong and many coastal cities in Japan, Taiwan, and South Korea have changed the outlines of their coastal for a variety of purposes. For example, South Korea has reclaimed more than 62,000 hectares of its coastal area since the Second World War, and it adopted a National Reclamation Master Plan in the 1980s in order to reclaim more land (Hwang 1999; Moores \& Braunlich 1999). In Hong Kong, most of the country's developed area is a reclaimed land and more been planned, including a project that provide space for a Disney theme park (Jiao, 2000). These activities show that coastal reclamation has become one of the main solutions for a land shortage issue. Nonetheless, reclamation would alter the condition and ecosystem of the coastal area in several aspects thus lead to the change in the quality of life of the local community living near to the coastal area.

This paper aimed to highlight the impacts of coastal reclamation to the quality of life of the community lives in Tanjung Tokong. It identified the variables of the quality of life involved, investigates the relationship of those variables and proposed a policy implementation in improving the adverse situation. It also reviews various literatures derived from online database, journals, articles, Environmental Impact Assessment reports, government papers and guidelines from local and overseas.

\subsection{Literature Review}

\subsection{Coastal reclamation}

Land reclamation is a process to create new land from the sea. As been highlighted by $\mathrm{Ge}$ Yu \& Jun- yan (2011), reclamation of marine is the important utilization of ocean for mankind to produce goods and provide living space for human. Further reported by Ismail et al. (1990), a number of sites along the coast in Bahrain have been either dredged or reclaimed to serve the industrial and residential purpose. Land shortage usually becomes one of the main solution in running a coastal reclamation projects. Because of the need for landmass, 
coastal reclamation is increasingly a popular response to perceived need for more space in many Southeast Asian cities. For example in China, with the extension of non-agriculture land use and shortage of cultivated land, the extension from land to sea has become one of the solutions to buffer the conflict of man and land shortage. Ramly (2008) stated that because of the land limited while the number of the population increased continuously, many of develop country adopted coastal reclamation. The countries which adopted the coastal reclamation projects in Asia are Malaysia, Indonesia, Singapore, China, Japan, Bahrain, and Hong Kong.

As coastal area is a very sensitive area, any development needs to be highly evaluated for its possible disturbances. It is because the coastal reclamation comes with its adverse impacts to the land. As argued by Adger (2005), hazard in the coastal area found through erosion activity and also caused by environmental change and human actions. If ecosystem undermined, the ability of the coastal areas to adapt and regenerate would erode.

\subsection{Issues of Coastal Reclamation to the Quality of Life}

Wetland continues to be converted into upland due to the development, agriculture, and silviculture (Magnusson, 2006). In Batam Indonesia, the reclamation had reduced the function of the mangrove forest to hold the water excess due to the rain and the up-tide. It reduced the total mangrove area from $24,000 \mathrm{~m}^{2}$ to $2,500 \mathrm{~m}^{2}$, and this had affected the society nearby when the area flooded during high up-tide, and the wave is strong (Priyandes \& Majid, 2009). In addition, mangroves known to provide protection for the community closed to its area. Swaminathan (2008) highlights that in an area where estuary was sustainable, mangrove and reefs absorbed the onslaught of the tsunami. He added that the mangroves in the Pitchavaram and Muthupet regions of Tamil Nadu acted as a shield in protecting the area from tsunami. Other part of degraded shoreline in India was restore to optimize the ability of coastal zones to provide ecosystem services for local communities. It resulted in an improvement of livelihood and environmental stewardship.

The impacts of waves on coastal areas due to the reclamation would be further increased, and the phenomenon of seawater intrusion will increase in sequence ( $\mathrm{Yu} G \mathrm{Ge} \&$ Jun-Yan, 2011). This situation is largely unlike by community in the area. The increased of waves impact would become a hazard to them, and coastal erosion potentially occurs. The sea water intrusion also affected the agriculture activity of the community as the salinity of the groundwater increase (Ismail et. al, 1991). The reclamation project in Tanjung Tokong also has a concern on erosion problem when ERINCO (1993) expressed their fear that there is a possibility of sand or soil erosion during the reclamation process. However, according to Abdullah (1993), National Coastal Erosion Study in 1984/1985 (Economic Planning Unit, 1985) had identified that the primary cause of coastal erosion is poor siting, planning and design of coastal development projects and activities.

The impacts of reclamation not only limited to the area where dredged and reclaimed occurred, but impacts felt over a larger area where siltation or change in current happened. For example, Ismail et al., (1991) emphasized that in Bahrain, the increased salinity of groundwater due to the mixing of seawater with ground water in the dredged area, make 
the ground unsuitable for domestic or agricultural uses. Reclamation affected groundwater and blocked the natural agriculture drains which lead to rise of water tables, intrusion of seawater and increase salinity in soils and groundwater. When domestic and agriculture output affected, it not only reduced the income of farmers but would also affect the population leading to an increase in food import, which brings implication to the national food security (Ismail et al., 1991).

The process of cutting hills around the district of Bengkong and Batu Ampar for reclamation purpose also caused high erosive lines which resulted in sedimentation when rainy season occurred, increased flooding point and affected water quality (Priyandes \& Majid, 2009). These will become a hazard to community living close to the area when their place flooded. The loss of ecological diversity will result a weaken protection against erosion of shoreline which increase vulnerability to storm surge (Hall, 2001).

The degradation of coastal zones affect human indirectly as human health is depending on the natural ecosystem. Although we may not live within a certain environment, environment health may indirectly affect us. For example, forests complex ecosystems provide important habitats for a certain species in that area which may be relevant to human health. If these complex relationships disturbed, there might be negative impacts on human health (Petersmack \& Wilkerson, 2003). Apart from the lost of beaches, the loss of wetland which works as the air filtration, would also affect health and increase the potential disease spreading (Taylor Patz et al.,1994). Apart from it, the unmanageable of rubbish disposed and solid material from the reclamation project also contributes to the health problem, breeding of flies, bad smells and contaminate beach area turned the area unsuitable for the community (ERINCO, 1993).

ERINCO (1993) added that traffic interference due to the movement to the site intends to send or disposed waste construction material expected to occur during reclamation project of Seri Tanjung Pinang. Moreover, Nasuchon (2009) worried that an increased of hotels, resort, restaurant and all activity related with the tourism industry can lead to water pollution. He added that this pollution originated from waste water from hotel, resorts and restaurant and also trash from tourism boats and ships. Tourism industry would be damaged as tourists prefer to visit natural scenic and cultural areas which are exceptionally delicate.

\subsection{Methodology}

\subsection{Case study research}

Yin (1984) introduced case study research as an empirical inquiry that investigates a contemporary phenomenon within its real life context, when the boundaries between phenomenon and context are not clearly manifest. Soy (1997) added case studies emphasize detailed contextual analysis of a limited number of events or conditions and their relationships. However, Hartley (2004) stressed that social scientists have made wide use of this research method in examining contemporary real-life situations and providing the basis for the application of ideas and extension of methods. Soy (1997) explained that 
case study research targeted a condition and their inter-relationship. The statement supported by Hartley (2004) who suggested that the case study method is precisely to understand how process influenced by and influence context. He added that many case studies researches use a combination of method because complex situation may be best approached through several methods to triangulate data and theory (and thereby improve validity). Stake (1978) points out that case study can be highly statistical which use for the institutional research. As a result, this research adopted a case study research as it involved a relationship data collected over a period and real-life situations and provide the solution for the problem arise.

Primary data collected using questionnaire survey and interviews where questionnaire survey is the primary instrument used for the study. This method produces numerical characteristic of data. The interview was the secondary instrument to support the primary data. Interview is an important aspect of many action research studies and of case studies whether undertaken by participants or outsiders. A fast and reliable method such as questionnaire survey is the most essential to the Tanjung Tokong area. Edward (2000) stressed that survey and interviews are two excellent methods for identifying social and economic goals of the community. Thus, this research is mainly a quantitative and qualitative research.

\subsection{Research population and sample}

A small, but carefully chosen sample used to represent the population. The sample reflects the characteristics of the population. According to Sekaran (2000), sampling is the process of selecting a sufficient number of elements of the population. The main reason to study and understand sample and its characteristic is to ensure the possibility to generalize the properties or the characteristics of the population elements (as cited in Bachok, 2011). Probability sampling conducted in the study was using stratified sampling. Stratified sampling is a common method that in advanced than random sampling as it reduces sampling error. With the level of precisions, $5 \%$ and confidence level $95 \%$ the sample size will be able to reflect the population (Israel, 1992). It means that within 95 out of 100 samples will have the true population value within the range of precision specified of the total community. Thus, 300 respondents were involved in the questionnaire survey. The eligibility criteria were as followed:

Residents live within $1 \mathrm{~km}$ setback from reclamation area;

Original community (respondent) lives within the period of reclamation which is before 2004; and Focus only on residential that resided and existed before 2004.

The interviews involve 7 respondents from various background to ensure that all of the opinion being heard. The interviewee was the teacher (R1), restaurant manager (R2), shop owner (R3), elder (R4), government staff (R5), JKKK (R6) and university student (R7). 


\subsection{Research limitation}

The scope of this paper concentrates only on Tanjung Tokong community as Tanjung Tokong area is one of the on-going coastal reclamation projects in Malaysia. Therefore, the impacts on the community and the change in communities' quality of life can be expected. Furthermore, this paper identify only the quality of life variable of community in Tanjung Tokong and investigates the relationship among those variable in determining the impacts. There are twelve variables identified which are job opportunity, property values, shop and malls, passive recreation, awareness of side effect, flash flood, air pollution, noise pollution, water pollution, traffic congestion, health and development. Therefore, it is more relevant to target the community in Tanjung Tokong as they directly influenced by the projects as compared to other area.

\subsection{Methods of analysis}

In a quantitative research, the information that obtained from the respondent should be expressed in numerical form (Eysenck, 2004). For that reason, the questionnaire survey data analyzed using Statistical Package for the Social Science (SPSS) version 17.0 software. The data entered into the database was analyzed using descriptive analysis, correlation and multiple correlation analysis. The result of the surveys is presented in a table, graph and chart as according to Eysenck (2004), it is understandable compared to present it in central tendency and dispersion.

\subsection{Findings and Discussions}

\section{Impact of coastal reclamation on the quality of life}

This division presents the finding of affected respondents in term of quality of life after the development of Seri Tanjung Pinang. The investigated quality of life consists of job opportunity, property value, shop and malls, passive recreation, side effects and health. The mean and standard deviation of the quality of life presented in Table 1. The highest mean was health $(M=3.78)$ followed by awareness of side effect $(M=3.73)$, quality of life increase $(M=3.69)$, important shops and mall $(M=3.61)$, noise pollution $(M=3.02)$, traffic congestion $(M=3.00)$, passive recreation area $(M=2.90)$, air pollution $(M=2.85)$, flash flood $(M=2.74)$, water pollution $(M=2.20)$, Seri Tanjung Pinang development $(M=1.77)$ and job opportunity $(\mathrm{M}=1.67)$.

A correlation test conducted to determine whether there is any relationship between quality of life and job opportunity, property values, shop and malls, passive recreation, awareness of side effect, flash flood, air pollution, noise pollution, water pollution, traffic congestion, health and development. The result presented in Table 2. The results suggest that nine variables significantly correlated with quality of life which are retails and malls, awareness of side effect, flash flood, air pollution, noise pollution, water pollution, traffic congestion, health and development. However, only two variables correlate positively 
Table 1: Mean and standard deviation of the quality of life

\begin{tabular}{|c|c|c|c|c|c|}
\hline $\mathrm{N}$ & & Minimum & Maximum & Mean & Std. Deviation \\
\hline Quality of life & 300 & 1 & 5 & 3.69 & 1.260 \\
\hline Job opportunity & 300 & 1 & 5 & 1.67 & .968 \\
\hline Shops and malls & 300 & 1 & 5 & 3.61 & .935 \\
\hline Passive recreation & 300 & 1 & 5 & 2.90 & 1.066 \\
\hline Awareness of side effects & 300 & 1 & 5 & 3.73 & .912 \\
\hline Flash flood & 300 & 1 & 5 & 2.74 & 1.188 \\
\hline Air pollution & 300 & 1 & 5 & 2.85 & 1.170 \\
\hline Noise pollution & 300 & 1 & 5 & 3.02 & 1.148 \\
\hline Water pollution & 300 & 1 & 5 & 2.20 & .902 \\
\hline Traffic congestion & 300 & 1 & 5 & 3.00 & 1.068 \\
\hline Health & 300 & 1 & 5 & 3.78 & 1.002 \\
\hline Development & 300 & 1 & 5 & 1.77 & .904 \\
\hline
\end{tabular}

Likert scale attributes: 1-Strongly agreed, 2- Not agreed, 3-Moderately agreed, 4-Agreed, 5- Strongly agreed.

Table 2: Correlation between quality of life and variables

\begin{tabular}{lllll}
\hline No. & \multicolumn{1}{c}{ Variable } & Correlation & Significance & Strength of relationship \\
\hline 1 & Job opportunity & $r=.072, p>.05$, two tails & Not significant & Small \\
2. & Shop \& malls & $r=.127, p<.05$, two tails & Significant & Small \\
3 & Passive recreation area & $r=.078, p>.05$, two tails & Not significant & Small \\
4. & Awareness of side effect & $r=.33, p<.01$, two tails & Significant & Medium \\
5. & Flash flood & $r=-.41, p<.01$, two tails & Significant & Medium \\
6. & Air pollution & $r=-.31, p<.01$, two tails & Significant & Medium \\
7. & Noise pollution & $r=-.24, p<.01$, two tails & Significant & Small \\
8. & Water pollution & $r=-.24, p<.01$, two tails & Significant & Small \\
9. & Traffic congestion & $r=-.28, p<.01$, two tails & Significant & Small \\
10. & Health & $r=.45, p<.01$, two tails & Significant & Medium \\
11. & Development & $r=-.16, p<.01$, two tails & Significant & Small \\
\hline
\end{tabular}

Table 3: Correlation between each predicators and quality of life

\begin{tabular}{|c|c|c|c|}
\hline M & \multicolumn{2}{|c|}{ SD } & \multirow{2}{*}{$\begin{array}{l}\text { Correlation between each predictors and } \\
\text { quality of life } \\
.127\end{array}$} \\
\hline Shops and malls & 3.61 & .935 & \\
\hline Awareness of side effects & 3.73 & .912 & -.332 \\
\hline Cause flash flood & 2.74 & 1.188 & -.408 \\
\hline Air pollution & 2.85 & 1.170 & -326 \\
\hline Noise pollution & 3.02 & 1.148 & -.241 \\
\hline Water pollution & 2.20 & .902 & -.234 \\
\hline Traffic congestion & 3.00 & 1.068 & -.280 \\
\hline Health & 3.78 & 1.002 & .448 \\
\hline Development & 1.77 & 0.904 & .163 \\
\hline
\end{tabular}

A post hoc test required to identify among all significant correlation variable (retails and malls, awareness of side effect, flash flood, air pollution, noise pollution, water pollution, traffic congestion, health, development) with the quality of life, which variable contribute the most. Therefore, standard multiple regression analysis used to evaluate the relationship. The predictors were retails and malls, awareness of side effect, flash flood, air pollution, noise pollution, water pollution, traffic congestion, health, development while the criterion was quality of life. The linear combination of retails and malls, awareness of side effect, flash flood, air pollution, noise pollution, water pollution, traffic congestion, 
health, and development significantly related to the quality of life, $F(9,290)=14.94, p=.00$ at .05 alpha level.

The sample multiple correlation coefficient was . 56 indicating that $32 \%$ of variance in the quality of life can be explained by a set of predicators (retails and malls, awareness of side effect, flash flood, air pollution, noise pollution, water pollution, traffic congestion, health and Seri Tanjung Pinang development). The descriptive statistic and bivariate correlation between each predicator and the overall quality of life presented in Table 3.

Based on coefficient result, only three of the independent variables are making statistically significant contribution to the predication of quality of life which are flash flood, traffic congestion and health.

Health (Beta= $.328, p=.00$ at .05 alpha level) make the strongest contribution to the quality of life followed by a flash flood (Beta= -. 20, $p=.003$ at .05 alpha level) and traffic congestion (Beta=-.11, $p=.04$ at .05 alpha level). As a result, the multiple regression result suggests that flash flood, traffic congestion and health influenced the quality of life the most.

Therefore, the analysis proves that there is a significant correlation between quality of life with retails and malls, awareness of side effect, flash flood, air pollution, noise pollution, water pollution, traffic congestion, health, development. However, only flash flood, traffic congestion and health influenced the quality of life the most. Flash flood and traffic congestion negatively correlated with quality of life while health positively correlated with quality of life.

From the interview, four of the respondents, R1, R2, R3 and R7 suggest environmental problem was the main issues. R1 believe she had experienced flash flood in recent years. R1 stated that "...I find the area were clouded with haze during the development and after it there was a flash flood. However, it only involve the side of the road and rarely affected people nearby..."

Another respondent, R2 added that as people move in Tanjung Tokong, air pollution becomes substantial. R3 also noticed that air pollution caused by the development during the reclamation process. R3 stated, "During reclamation phase, dust was everywhere. However I think that today is better, but we had much more better experienced than this" R7 expressed his concern, as in recent years, Tanjung Tokong had turned into a busy town. He mentioned that, "During the reclamation process previously, there were tons of lorries going in and out of the site for reclamation. At that time, the area was dusty. Air pollution was a significant problem during that time."

Matsuoka (1994) had notified that any temporary increase in noise and dust pollution caused by construction reclamation work gives a negative psychological and physical impact to the people around. Patz (1994) also stressed on the loss of wetland which works as air filtration could cause a problem to public health and increase disease spreading. R5 supported the statement by stated, "With more people move in Tanjung Tokong, development, the lost of all nature, and environmental problem I got sick all the time. I'm not sure if Tanjung Tokong is still a great place to stay as in the oldies time."

Therefore, the analysis proves that there is a significant correlation between quality of life with retails and malls, awareness of side effect, flash flood, air pollution, noise pollution, water pollution, traffic congestion, health, development. However, only flash flood, traffic congestion and health influenced the quality of life the most. Flash flood and traffic congestion 
negatively correlated with quality of life while health positively correlated with quality of life. It found that community of Tanjung Tokong aware of the side effect of coastal reclamation of them. Noise pollution, flash flood and air pollution make the biggest contribution of the awareness.

Reviews of the literature identified the lost of mangrove is one of the reasons that cause the area near the coastal flooded (Priyandes \& Majid, 2009; Swaminathan (2008). Apart from the lost of beaches, the loss of wetland as the air filtration would also affect public health and increase the potential disease spreading (Patz et al.,2004; Magnusson, 2006; Petersmack \& Wilkerson, 2003). Priyandes and Majid (2009) added that the reclamation materials and pollutants generated during the reclamation activities, pollute the marine environment. This problem known to affect the fisheries activities. At some extent pollution can be controlled, but the ecological and environmental impacts of reclamation cannot be restored. It can be concluded that the development of Seri Tanjung Pinang had caused an environmental problem thus, affected community quality of life.

One of the suggested policies is public participation in any decision making done by the developer and authority. A community leader elected among the communities and should be invited and represent the community's voice and opinion on any of their dissatisfaction. With the public participation also, the leader able to inform the community of any incoming problems or issues on the development. This two way process helps in understanding the issues on communities' side, developer and authority interest which can avoid any dispute.

Next, a survey can also help in minimizing the impacts of coastal reclamation to the community socio- economic. By surveying, communities' problem and request can be acknowledged in improving their quality of life. Socio-economic impact Assessment is one of the instruments in analyzing the incoming impact of the development. A statistic result will help in understanding how much the impact will generate. This can assist in decision making and planning for the development.

Apart from it, community can have the benefit from the development in terms of tourism and employment provided by the developer. Coastal area has a unique character which usually been utilized in the tourism industry. Community should have the opportunity to work in the developed area. As part of socio-economic sustainability, tourism businesses can be promoted by conventional and modern marketing techniques that ensure adequate access of local tourism small and medium enterprises (SMEs). The developed area also can be utilized as a passive recreational area.

Observation also should be done from time to time. It is to ensure that the community adapted to the new environment. As mentioned by Abdullah (1993), coastal zones are rich in resources which can harness for the social economic growth of the country. He stressed the importance to recognize that the sustainable development or utilization of these resources must be funded, for an approach that gives consideration to the importance and sensitivity of the coastal process and environment. 


\subsection{Conclusion}

This paper had discussed how the coastal reclamation affected the quality of life. The analysis proves that there is a significant correlation between quality of life with retails and malls, awareness of side effect, flash flood, air pollution, noise pollution, water pollution, traffic congestion, health, development. However, only flash flood, traffic congestion and health influenced the quality of life the most. Flash flood and traffic congestion negatively correlated with quality of life while health positively correlated with quality of life. It found that community of Tanjung Tokong aware of the side effect of coastal reclamation of them. Noise pollution, flash flood and air pollution make the biggest contribution of the awareness.

The impacts of coastal reclamation to the quality of life have clearly been outlined. Nevertheless, it is almost impossible to ensure that the community would not be affected at all by reclamation activities. However, coastal reclaim is quite significant in well-developed countries, which need more land to sustain their economics. To evaluate a reclamation project, a cost-benefit is one of the methods that can be used to determine whether the project has more advantage than disadvantage. A policy on coastal reclamation should be introduced and must be applied to all nations not only to protect the natural environment from destruction but also to the nearby community. As we depend on the environment, we must respect it accordingly by behaving and acting wisely in relation to the management of the valuable natural and physical environment.

\section{References}

Adger, W.N. (2005) Social Ecological Resilience to Coastal Disasters, Science, www.sciencemag.org [accessed: 2011, September 14]

Abdullah, S., \& Hiew, K. L. (1997). Keynote address: Coastal Reclamation in Malaysia, Regional Seminar on Land Reclamation for Urban Development. University Malaya

ERINCO. (1993). Tanjung Tokong Land Reclamation Project Pulau Pinang: Preliminary Environmental Impact Assestment.

Edwards, M. (2000). Community Guide to Development Impact Analysis. Madison, WI: Wisconsin Land Use Research Program (May).

Ge Yu., \& Jun-yan, Z. (2011). Analysis of the impact on ecosystem and environment of marine reclamationA case study in Jiaozhou Bay. Energy Procedia 5; Elsevier. Vol. 5, pp. 105-111

Hall, C.M. (2001) Trends in ocean and coastal tourism: the end of the last frontier? Ocean and Coastal Management. Pp 1-18 Hwang, M. (1999).Coastal Land-use Change by Reclamation of Tidal Flats along the Western Coast of the Capital Region in Korea. Seoul National University, Seoul, Korea.

Hartley, J. (2005). Essential Guide to Qualitative methods in Organizational Research. Atherbaeum Press Ltd, Gateshead

Israel, G.D. (1992). Sampling the Evidence of Extension Program Impact. Program Evaluation and Organizational Development, IFAS, University of Florida. PEOD-5.

Ismail M. Al-Madany et al. (1990), Coastal Zone Management in Bahrain: an Analysis of Social, Economic and Environmental Impacts of Dredging and Reclamation. Journal of environmental management, Vol 32, pp. 335-348. 
Jiao, J.J. (2000) Preliminary Conceptual Study on the Impact of Land Reclamation on Groundwater Flow and Contaminant Migration in Penny's Bay.Department of Earth Science, University of Hongkong.

Majid.N.A.R. (1985) A Review of Coastal Zone Legislation in Malaysia.Environmental. Protection and Coastal Zone Management in Asia and the Pacific, pp. 61-64

Moores, N., \& Braunlich, A. (1999).“The Saemankum Project".

Magnusson, G.S. (2006). Economic-Ecological Relationships in Coastal Wetland Restoration. Unpublished PhD's thesis. University of Rhode Island

Priyandes.A.,\& Majid. M. Rafaee. (2009) Impact of the Reclamation Activities on the Environment Case Study: Reclamation in Northern Coast of Batam. JurnalAlamBina, Vol. 15, pp. 21-34

Petersmack, P., \& Wilkerson. R. (2003) Land Use Affects Public Health

Patz, J.A., Daszak, P., Tabor, G.M., Aguirre, A.A., Pear, M., Epstein, J., Wolfe, N.D., Kilpatrick, A.M., Foufopoulos, J., Molyneux, D., Bradley, D.J. (2004) Unhealthy Landscapes: Policy Recommendation on Land Use Change and Infectious Disease Emergence, Environmental Health Perspective, Vol. 112, pp. 1092-1098

Ramli, S. (2008). Impact on the coastal areas of the Tanjung Tokong Land Reclamation Project, Penang, Malaysia, Effects on wave transformation, sediment transport, and coastal evolution. LTH, Lund University. Sweeden.

Soy, S.K. (1997). The case study as a research method. Unpublished paper, University of Texas at Austin

Swaminathan, M.S. (2008) Valuing ecosystem service of coastal zones. Environment matter annual review.Pp. 8-9

Wang, X., Chen, W., Zhang, L., Jin, D., \& Lu, C. (2010) Estimating the ecosystem service losses from the proposed land reclamation projects: A case study in Xiamen. Ecological Economics: Elsevier. Vol. 69, pp.2549-2556.

Xu, M., \& Wang, J. (2003). Influence of coastal reclamation in Zhangzhou Port on Coastal Evolution of Neighbouring Sea Area. International Conference on Eusteries and Coast. Pp.352-359

Yin, R.K. (1984). Case study research: Design and methods. Newburry Park, CA: Sage.

Zeballos, C., \& Yamaguchi, K. (2011) Impacts of land reclamation on the landscape of Lake Biwa, Japan. ProcediaSocial and Behavioral Sciences: Elsevier. Vol.19, pp.683-692. 